\title{
e-HRM within an African Context
}

\section{Jealous Sungwa}

Faculty of Human Resources Management, College of Economics and Management Sciences, University of South Africa (UNISA), Pretoria, South Africa

Email: jealoussungwa@gmail.com

How to cite this paper: Sungwa, J. (2021) e-HRM within an African Context. Open Access Library Journal, 8: e7596.

https://doi.org/10.4236/oalib.1107596

Received: May 29, 2021

Accepted: July 24, 2021

Published: July 27, 2021

Copyright $\odot 2021$ by author(s) and Open Access Library Inc.

This work is licensed under the Creative

Commons Attribution International

License (CC BY 4.0).

http://creativecommons.org/licenses/by/4.0/

\begin{abstract}
The aim of this paper is to explore the perspectives about e-HRM in an African context and how these perspectives relate to organizational outcomes. This study is based on the CRANET research results on HRM practices in South Africa. This study acts as a preliminary study of e-HRM and will lead to more involving comprehensive studies.
\end{abstract}

\section{Subject Areas}

Human Resource Management

\section{Keywords}

e-HRM, HRM, HRIS, Strategy, HR

\section{Background Information}

Many scholars such as Ruel \& Kaap (2012) [1], Nivlouei (2014) [2], and Strohmeier \& Kobst (2014) [3], institute that e-HRM is increasingly advancing and leading organizational changes. The whole world has entered an era where everything we do is influenced by electronic developments propounded by globalization and rapid evolution of global economic knowledge. In 1999, Bill Gates [4] stated that the internet was a tidal wave which is going to wash over all organizations and in so doing might drown individuals not learning to swim in its waves. As a follow up to this statement HRM proponents propose that HRM occupies a strategic position in all organizations. They establish that HRM is paramount in organizational wealth creation and this is a crucial need in Africa to enable development. Effective and efficient $\mathrm{HR}$ ascertains generation of organizational value. The nature of HRM in Africa has not drastically changed. The HR departments continue rendering services to customers. The customer tastes, demands and likes constantly change thus providing huge challenges of improving 
the service quality to enable organizational survival and development. Regardless of what HRM departments in Africa are doing seems administrative and transactional, there is a growing urgent need to close the gap between customers' changing needs and the nature of the product and service quality rendered. The main focus is to attain organizational objectives of which the major one is to satisfy customer's demands. Customer satisfaction contributes boldly to organizational effectiveness in a strategic way. Organizations should not turn a deaf eye on the HRM costs. Although many African organizations have adopted technology as an SHRM handy tool to employ in addressing HR challenges. It has been noticed that technology has been established in Africa through forms of experiments. The technological experiments have emanated in Africa in 1960 and just like all other parts of the world, technology is now a way of life. This is very common mostly in HRM. Elliot and Teravichulada (1999) [5] indicate that African HR departments were using technology to render integrative services to enable free communication in electronic businesses; this is a complex fusion of business process enterprise application and firm structure to improve performance in a business model.

Surprisingly many organizations faced huge challenges in replacing the traditional HRM practices with e-HRM; however proponents of electronic-Human Resources Management have attested that it enables the HR function to contribute effectively, efficiently by creating strategic capabilities and competencies for an organization. This article evidenced results from the CRANET (2011) study on HRM practices in South Africa which indicates that organizations in South Africa use e-HRM for all HR practices ranging from recruitment to training and record keeping. The results from this study were generalized in an African context.

Focusing on enormous changes been brought to African economy with increased technological developments, mostly the introduction of the computers and internet. Recently technological development has taken a new wave of (HR) human resource. This is referred to as electronic human resource management (e-HRM) [6]. Strohmeier (2007) [7] gave a definition of e-HRM as the use of IT in support of HR managers in conducting HRM activities. The e-HRM was introduced to facilitate effective, efficient and strategic HR practices. Scholars like Strohmeier (2007) [7] confer the reason of introducing (e-HRM) as to provide human resource (HR) departments with a chance to participate in a bid to lead organizational success. This study review issues on e-HRM in an African context in detail evidence was provided by a study on e-HRM in South Africa. The research used these results and generalize that what was happening in South Africa is generally the same in other African states. This paper is anticipated to help readers understand e-HRM in an African context more comprehensively.

\subsection{The Theoretical Framework}

HRM literature stipulates that e-HRM activities have many aspects that bare potential hazards that counterfeit the strategic implementation of HRM competen- 
cies and systems. It is important therefore to scrutinize these aspects so as to help understand how the e-HRM practices prestige organizational SHRM outcomes. The integrative theoretical Framework originates from the framework by Strohmeier (2007) [7] was used to elaborate e-HRM research topics. Strohmeier (2007) [7] proposes that e-HRM outcomes can be determined by configuration theory. This paper examines the effects of technology, and HRM theories mainly configurationally; resources-based view; systematic agreement theory; the multiple stakeholder perspective theory and the strategic reference point theory on organizational effectiveness. This study examines how the actors of e-HRM have both been affected by the use of e-HRM and how the implementation of e-HRM has led to strategic gains. Deryet et al. (2013) [8] indicate that interaction between technology and workers is a common trend which can easily be found in e-HRM literature. On the other hand, Arvidsson et al. (2014) [9] state that information systems use a strategy just like HRM in achieving its goals. This facilitates the study to view both e-HRM and HRM from a strategic view.

\subsection{The Research Problem}

Although the research in the domain of e-HRM is progressing, according to Strohmeier (2007) [7] many researchers such Bondarouk et al. (2011) [10] argue that there is relatively little evidence in research on e-HRM in the whole world apart from the United States. Olivas-Luján and Florkowski (2009) [11] saw that research on e-HRM was Western-based and only very few e-HRM studies have been done in other contexts. This paper aims at elaborating the adoption of electronic Human Resources Management focusing on the African perspective which resembles an emerging economy. The e-HRM adoption in Africa is drifting from Human Resources Information Systems to e-HRM. This takes place when organization supports the HR department to act as a business partner in that organization through strategic planning, redesign human resources practices, providing customer services to employees, providing rich and highly integrated information to both managers and workers [12]. This study focuses on the conditions that influence the adoption of e-HRM on emerging economies. This paper would also assess the importance of SHRM theoretical contributions in an African context. With this in mind, our research is guided by the following research question: What influences the adoption e-HRM in organizations in Africa?

\subsection{Significance of Study}

First, the research elaborates the conditions of the electronic Human Resources Management arena, emphasizing the link between IT and HRM concepts. Previous scholars fail to realize the importance of one of these concepts to the organizational effectiveness on its own, on the contrary, this study offered to conceptualize both Information Technology and Human Resources in one study so as to determine their impact on organizational outcomes. Second, this study in- 
dicates the kinds of practices in which e-HEM users will engage and the type of knowledge they will produce, realize, and promote. The third contribution is that the study demonstrates the effects of power of e-HRM system on organizational performance, efficiency and effectiveness.

\subsection{Aim of Study}

To assess the electronic Human Resources Management adoption levels in Africa.

\subsection{Research Objectives}

- To find out the level of adoption of information and technology in an African context.

- To assess the effects and efficiency of information and technology in African organization.

\subsection{Research Questions}

- To what level have both public or private organizations in African states have managed to incorporate e-HRM in running their HR functions.

- What benefits accrue to SHRM functions by utilizing e-HRM systems in all the HR practices?

\section{Review of Related Literature}

\subsection{Previous Studies}

Literature reveals that there are several studies carried out on e-HRM:

- Francis et al. (2014) [13] studied the implementation of e-HRM that affect worker relationships; they discovered negative effects on the relationships between middle managers HR departments.

- Burbach and Royle (2014) [14] explored that factors such as individual, relational, organizational and external (institutional) determine the success implementation of an e-HRM.

- Martin-Taylor (2013) [15] examines how one could improve e-HRM adoption by involving employee knowledge in initial e-HRM planning and he found out that the HR department providing a pivotal role in improving worker perception.

- Grant and Newell (2013) [16] examine subjects such as personnel and technology used so as to realize the e-HRM strategic potential.

- Barret and Oborn (2013) [17] examined the requirements of running an e-HRM and realized that project management skills were necessary in the selection for e-HRM workers.

- Khera and Gulati (2012) [18] carried out a study on Human Resources Information System and its impact on HR Planning; they provided a perceptual analysis on ICT in organizations. Their conclusion indicated that HRIS easily establishes both occupied and unoccupied organizational positions in an ac- 
curate and effective way.

- Bader (2012) [19] analyzed the link between (HRIS) practices and (HRM) departments and it was realized that performance management, talent management, and training management are components of HRIS.

- Tripathi (2011) [20] developed a management information systems model by analyzing the MIS role in HRM. The model was designed to help control workers at various organizational levels.

- Chiemeke (2011) [21] carried out a study on HRIS aimed at developing an integrated research agenda whose aim was to set HRIS research agenda for an integrative theoretical framework.

- Gupta and Saxena (2011) [22] investigated on the management satisfaction towards e-HRM.

- John (2008) [23] reveals that HRIS enables quicker HR activities, reduces errors, enables more data collection, and reduces labor costs; it reduces duplication and improves distribution of information.

- Olivas-Lujan et al. [24] and Strohmeier \& Kabst (2009) [25] carried out studies on the adoption of e-HRM.

- Bell et al. (2006) [26] tested the impact of e-HRM on management competence in Human Resources Management.

\section{Gap Left by the Previous Studies}

Despite the good results from the employment of e-HRM, very little knowledge has been gathered that built powerful relationships between HR function and electronic-Human Resources Management systems as strategic partners [8] [27] [28] [29]. The disparity between HR functions and e-HRM is supported by the study of Marler and Fisher (2013) [30] who argue that even if e-HRM data seems to be very clear, very little evidence supporting this by providing a direct causal effect between e-HRM systems and organizational strategic outcomes. Strong studies reveal that on numerous incidents the HR department remains administrative and thus failing to participate in strategy implementation. In this regard on the notion that IT could change the HR function falls short.

\subsection{The Perspectives of Strategic Human Resources Management}

\subsubsection{Resource Based View}

The RBV of an organization deals with the provision of good investment and the development of the organizational human resources to enable increase in value to an organization. An organization that acquires and trains employees can obtain an organizational competitive advantage. RBV aims at achieving the strategic fit between opportunities and resources to obtain an additional value from effective utilization of organizational resources. It is generally acknowledged that when adequately trained and effectively deployed, the human resource as an organizational asset, can contribute to organizational outcomes.

\subsubsection{The Multiple Stakeholder Perspective Theory}

The idea brought by the integration of a multiple stakeholder perspective in 
Strategic Human Resources Management issues is in systems theory [31]. The systems theory elaborates that firms operate as open systems rather than independent isolated organizations with the view of support provided by all the stakeholders. The power of the relationship between both the organizational and stakeholders' goals, objectives, together with the strategies pursued by the organization is the bottom line guiding the multiple stakeholder perspective theory.

\subsubsection{Systematic Agreement Theory (SAT)}

Systematic Agreement Theory structures a framework in which there is firm alignment of culture, strategies, and organizational designs to attain the intended objectives. According to Lengnick-Hall and Lengnick-Hall (2009) [32], the SAT framework is aimed at improving organizational effectiveness, achieve firm objectives and goals and create a sustainable competitive advantage. The theory employs four important aspects of firm alignment that is environmental, cultural, structural, and performance.

\subsubsection{Strategic Reference Point Theory}

Researchers show that when grouped together; the different perspectives like strategic intent, motivational theory, and resource dependence, provide a platform of reference points helping organizations to generate benchmarks. The benchmarks are used as organizational plans. Strategic Reference Point Theory proponents' states that there are two SRPT important concepts that affect firm effectiveness on Strategic Human Resources Management these are strategic fit and consensus. Strategic Reference Point Theory advocates suggest that the model provides a link between strategy and policy at the implementation stage indicating to managers established policies and practices to use.

\subsubsection{Configurationally Theory}

Proponents of this perspective suggest specific configurations of human resources activities which form Human Resources systems which help organizations in producing good outputs. When the Theoretical models that bind training to firm outcomes are incorporated in the training and development system, the configurationally perspective indicates that training improves firm outputs when employed together with other closely related Human resources practices than when it is used alone. Firm effectiveness can be observed when investment in training is consistent with other Human Resources activities. Human Resources practices related to training such as selection of applicants, activities to reduce employee turnover, internal promotion and the use of performance measurement and compensation.

\subsection{The Perspectives of e-HRM}

The review of literature of works by Strohmeier (2007) [7], Ruel \& Kaap (2012) [33] and Marler and Fisher (2013) [30], it emerges that the e-HRM major theoretical framework comes from the new institutional theory, the contingency 
theory and the transaction cost theory and the RBV theory. First, the Resource Based View theory states that workers are the most important resources of a company to gain sustainable competitive advantage [31]. Applying the RBV [30], theory in HRM, insist that investing in Human Resources help reduce cost through the improvement of the HR quality services, changing HRM function to become strategic business partners and restructuring HRM operations.

Kaur (2013) [34] elaborate that, the HRM's effects is on both effectiveness and efficiency of Human Resources Management practices on organizational performance. This is affected through the reduction of paper work. This leads to increasing data accuracy by eradicating excess manual HRM activities. Electronic Human Resources Management practices such as recruiting, learning, compensation, are all viewed as organizational objectives to mould valuable, unique non-imitable and non-substitutable employees.

Having looked at RBV is also important to look at the contingency theory as illustrated by Lawrence and Lorsh (1967) [35] who indicate that institutions are influenced by the environment. They stress that organizational success depends solemnly on the shape of the internal structure focusing on the environment. Ruel and Kaap (2012) [33] establish that an organization has to guide the micro and macro environmental factors and see that they fit well with the organizational structure together with other organizational variables to attain the needed outcomes. In addition to the contingency theory, the transactional cost theory when applied to e-HRM demonstrates how e-HRM can be a cost saving mechanism through outsourcing, decentralizing and delegated structures. All effective HR practices that help reduce costs in e-HRM are guided by the transaction cost theory. Having said this it is necessary to consider the fourth theory, which is the institutional theory that guides the e-HRM theoretical framework in that organizations should pay attention to their organizational expectations within their environments. They should also respond positively to market and marketing pressures. Strohmeier (2007) [7] illustrates that, institutional theory provides a link between the institutional perspectives with the e-HRM configurations. The institutional theory guides the e-Human Resources Management activities and those valuable aspects that affect the activities in order to generate new ways which will contribute to increased organizational output by creating a pool of human intellectual capital through knowledge management.

\subsection{System Overview in African}

\subsubsection{Evolution of e-HRM}

e-HRM is defined as technology used in sourcing and managing workers in an organization. e-HRM is used in human resource information systems (HRIS) HR professionals. This technology is accessed in many ways. e-HRM has enabled effective and efficient collating, gathering and delivering information in a dib to transmit information to workers. It is important to realize that e-HRM reduces the HR functional costs. Organizations that successfully employ e-HRM functions will manage to get an added advantage over their competitors. 


\subsubsection{Electronic Database System}

The adoption of relational database technology enabled firms to develop organizational reports which would link many components. A relational database gives provision of databases to be located in many different sites linking the same information. In addition, other departmental areas can receive information from these relational databases.

\subsubsection{Electronic Human Resources (e-HRM)}

e-HRM is a form of technology which enables HR functions to integrate processes and HR practices together with organizational SHRM aimed at improving the HR outcomes. With the involvement of e-HRM organization always cherish on cheaper managing ways, rendering good services, and managing human resources effectively. e-HRM is now regarded as an integral part to help firms achieve long-term goals.

\subsection{The Benefits of e-HRM}

Many scholars have provided useful insights on the benefits of e-HRM. These are:

Operational benefits

- Publishing information

- Administration of salaries

- Human resources activities in administrative departments

- Administration of personnel profile

$\underline{\text { Relational benefits }}$

- E-Human resources planning

$\circ$ E-recruitment and selection

- Automation of transactions

- Performing Human Resources function in digital form

- Online HR training and development

- E-compensation plans

- E-performance appraisal

Transformational benefits

- Strategic knowledge management

- Strategic competence management

- Strategic orientation

Even though e-HRM is associated with many benefits in HRM, proponents of e-HRM view e-HRM levels differently.

The first perspective was by Wright and Dyer (2000) [36] they view electronic human resources as:

- Transactional electronic HRM

- Traditional e-HRM

- Transformational e-HRM

Three years later, Lengnick-Hall and Martz (2003) [37] noted three forms of electronic human resources namely: 
- Publishing of information;

- Automation of transactions and;

- Transformation of human resources department.

Ruel et al.(2009) [33] elaborate that e-HRM is a system of demonstrating organizational strategies, HR practices, organizational strategies and policies with the support of and the use of selected internet channels. Electronic Human Resources Management is helped by information technologies in assisting organizations to recruit, deploy, and develop the human capital. In addition, Kulkami (2012) [38] states that Electronic Human Resources Management is a web-based technique taking advantages of the new technology to do online Strategic $\mathrm{Hu}$ man Resources Management activities. Most prominent proponents of SHRM consider e-HRM as a method for an organization to implement HR practices, policies and strategies by the use web-based technology. In Africa there is a general consensus that many organizations private and public, large and small, highly rely on e-HRM function in the provision of modern management solutions which lead to effective human capital. These practices range from electronic selection, recruitment, training, performance, compensation and employee profiling.

\subsection{The Best Practices of e-HRM Systems in Organizations}

African organizations have adopted the best practices of e-HRM such as electronic selection, recruitment, learning, training and performance management, compensation, employee profiling and career planning. e-HRM has been formulated aiming at maximizing the efficiency of the HR function in smoothening the procedures, reducing high recruitment costs, minimizing unnecessary administrative constraints and having organizations pursing a strategic role [39]. Evidence from a survey carried out by CRANET reveal that most African companies have adopted Lepak and Snell's three level model (1998) [40]. The three level models suggest that operational e-HRM level is the first one. HR planning systems that include salary administration and personnel profile administration.

The relational e-HRM is the second level that provides HR tools that aid in electronic selection, recruitment, training, employee performance appraisal and reward management. The third level, the transformational e-HRM covers issues of strategic in nature. This level entails all activities tailor made to support and promote organizational change processes. This mainly involves strategic change, strategic competence management and organizational environment management. Most organizations in Africa use knowledge systems, intranet and inner portals.

\subsubsection{E-Recruitment and E-Selection Process}

Recruitment is a crucial organizational practice that enables harnessing the most important resources into an organization. The ability to recruit high quality resources is a strategic need. This resource mostly guides organizations in gaining competitive advantage [27]. E-recruitment as part of e-HRM is known as the use 
of the internet to attract suitable qualified employees. Dhamiya (2012) [41] illustrates that online recruitment employs a particular website to interview, assess, and finally help hire most suitable worker. Tong (2009) [42] discovered that the involvement of e-recruitment is a time and cost reducing mechanism. When successful recruitment of strategic employees is done on time at reduced costs, organizations stay competitive. Organizations benefit through the use of online recruitment systems by disseminating valid information pertaining to specific job on offer. The would-be employees get an unfair share of viewing internal organizational information such as company web-page job description, job related incentives and even organizational culture. These potential workers are also shown visual images in the form of pictures, animations and videos. These images enable the potential workers to evaluate whether their individual work needs would be satisfied with the job offered.

\subsubsection{E-Training/E-Learning}

Bell (2007) [43] argues that most organizations have relegated the employment of the traditional training basing on problems such as fixed time, location or place. It has been noted that e-training out class the traditional training technique in that e-training takes place without specific training rooms, travelling costs, and most importantly without the presents of trainers. Interestingly, Kaplan-Leiserson (2002) [44] indicates that e-learning is believed to be a wide set of applications such as digital collaboration, wed-based learning, virtual classrooms, and computer-based learning. Sambrook (2003) [45] concur with Kaplan-Leiserson (2002) [44] by describing that e-learning is a set of activities focusing on learning which is backed by sets of information and communication technologies. This form of training can take place with the aid of the company's intranet, internet video conferencing and audio.

Quite a number of advantages have been attached to e-training. The major advantage is flexibility which allows learners to select most convenient venue and schedule. This reduces training costs ranging from opportunity, instructional, travel and administration. The advantage promotes worldwide organizational training. Comacchio and Scapolan (2005) [46] indicates that another advantage of e-training is talent retention, where organizations through e-training modify, develop and even enhance knowledge, skills, abilities and competencies which would enhance organizational effectiveness

\subsection{3. e-HRM Rewarding and Compensation}

Organizations use a variety of mechanisms to attract competent staff. A compensation policy is one area which has been proved to be effective in organizations. A good system enables firms to achieve organizational strategies by attracting employees who are competent, loyal, and commitment thus they resemble a direct positive impact on organizational outcomes. However even though the e-HRM rewarding system has benefits, there have been major criticisms from Manjunath and Rajesh (2008) [47] who argue that the rewarding system tends to ignore different performance levels and result in employees receiving 
same salary but would have different levels of performance and talents.

On the other hand, Dulebohn and Marler (2005) [48] remain resolute in support of e-HRM compensation and rewards. They proposed e-compensation tools such as web-based software would enable companies the proper assessment on performance through gathering, analyzing, utilizing, manipulating, distributing and storing employee compensation data and information. Dulebohn and Marler (2005) [48] assert that e-compensation tools may minimize bureaucratic levels by having real time information processing. Supporters of e-HRM such as Wright and Dyer (2002) [49] are of the idea that e-HRM would help workers to select electronically preferred benefits and rewards thus reduce administrative costs.

\subsection{4. e-HRM Performance Management}

It is noted that the complications associated with employee performance ranging from setting goals, planning, tracking, appraisal, evaluation and feedback of performance management. Bondarouk and Looise (2009) [50] suggested three types of employee e-performance management, operational, relational and transformational. Operational managers use technology solely to support performance planning process by filling in online forms. Managers communicate with the employees in the relational type. They do this using for example a $360^{\circ}$ feedback on performance in an organization. It is noted that transformational e-performance aims at a strategic approach. This is done by exploring and analyzing employee competencies as an individual and as aroup.

\subsection{Challenges in the Use of Hr Technologies}

The use of e-HRM in organizations is affected by many factors such as;

- Organizational Culture-Organizational culture disturbs the acceptance and the rate of both adoption and implementation of new e-HRM systems in a firm. People view technology differently for some they believe they get better results and accurate information with ease of use for some it is not the same.

- Security Concerns-An e-HRM system which is designed to suit one organization in a given country may not be effectively the same in other environments. This can be in the form of privacy of data and availability of data when needed.

- User orientation-Training should take place prior to use of e-HRM technology. The workers need to be well convinced in using technology that will assist them in realizing better and good quality results as compared to the old situation.

- Cost-The adoption and implementation cost are a very important factor for the organization to consider before acquiring the e-HRM systems. There is need for the organizations to budget priorities and select e-HRM systems that will be compatible to each other and to the whole organization.

- Training and development-Training and development in the process of e-HRM adaptation given a new e-HRM system is time involving and cum- 
bersome event. Training and development may present unique challenges for the trainers and user if they do not view it as user friendly.

- Technical limitation-The e-HRM system though it might seem good in an organization, the organizations need to have skilled labor with both technical knowhow and other human related skills. The organization will have a challenge of acquiring people with dual set of skills.

\section{Research Design}

\subsection{Research Approach}

This paper uses secondary data from the results of a survey of South African human resource management practices in private and public organizations the data was collected by University of South Africa (UNISA) working together with CRANET. The survey is part of a longitudinal, comparative study of human resource policies and practices involving 35 countries worldwide. The CRANET report provides an overview of the key findings of the South African survey.

\subsection{Research Methodology}

This questionnaire was designed to make completion as easy and fast as possible. Most questions can be answered by simply ticking boxes. Very little information was needed to be looked up. This questionnaire asks you about the Personnel/Human Resource (HR) policies and practices in the organization or part of the organization (Division, Business Unit, Department) for which you have Human Resource Management responsibility. The basis of the survey was a questionnaire completed by human resource managers on behalf of their organizations. The research reflects policies present in 2014. 155 companies in South Africa were used in the survey. Of these 155 large companies, 100 were privately owned, 50 were government enterprises and 5 were foreign owned.

\subsection{Research Participants}

South African private and public organizations

\subsection{Measuring Instrument}

The measuring instrument of the survey was a questionnaire completed by human resource managers on behalf of their organizations.

\subsection{Research Procedure}

The study used secondary data from the results of a survey of South African human resource management practices in private and public organizations the data was collected by University of South Africa (UNISA) working together with CRANET.

\subsection{Statistical Analysis}

Secondary data from the results of a survey of South African human resource 
management practices tables and descriptive statistics were used. The secondary data source is https://www.dcu.ie/link/cranet-international-human resource management.

\section{Results}

Table 1.47 indicates the use of HRIS for individual personnel records.

The results show that $87 \%$ (135 companies) use HRIS for their individual personnel records, while $12 \%$ (20 companies) do not. This is an extremely positive finding. Computerized staff records afford managers immediate access to staff information. This ultimately improves efficiency and effectiveness in a company. A total of 37 companies did not answer this question. Source: (https://www.dcu.ie/link/cranet-international-human resource management).

Table 1.49 indicates the use of HRIS for benefits.

The results show that 92\% (141 companies) use HRIS for their benefits, while $8 \%$ (12 companies) do not. This finding is not surprising when one looks at the results in table 1.48 regarding the use of HRIS in the area of payroll. Payroll and benefits are closely linked and using both with HRIS is inevitable. A total of 39 companies did not answer this question. Source:

(https://www.dcu.ie/link/cranet-international-human resource management)

Table 1.51 indicates the use of HRIS for recruitment and selection purposes.

The results show that $63 \%$ (98 companies) do not use HRIS for this purpose, while $36 \%$ (56 companies) indicated that they do. This is extremely disappointing since the use of HRIS in recruitment and selection has many advantages. For example, the system can be used to build up a database of possible future employees, for instance, potential candidates placing their particulars on the system should a vacancy occur. The system can also be used to identify suitable internal candidates for movement up the career ladder. Besides these advantages, the system can be used to test candidates electronically (i.e., doing tests online). There are thus numerous benefits in the use of HRIS in the area of recruitment and selection. Another disappointment was the large number of companies (38) that failed to respond to this question. Source:

(https://www.dcu.ie/link/cranet-international-human resource management).

Table 1.52 indicates the use of the HRIS for training and development purposes.

The results show that $45 \%$ (69 companies) do not use HRIS for this purpose, while 54\% (84 companies) indicated that they do. This is a positive finding. However, a large group of companies still need to do some work in this area. The use of HRIS in this area can provide numerous benefits-for example, all employee training can be placed on HRIS, which will allow easy access to line managers; it will also assist employees to ascertain what training and development opportunities are available to them and allow them to book online. Besides these benefits, it will also allow management to gain an overall view of what skills are available in the company. The fact that 39 companies did not answer 
this question is cause for concern. Source:

(https://www.dcu.ie/link/cranet-international-human resource management).

Table 1.53 indicates the use of HRIS for performance management purposes.

The results show that $47 \%$ (72 companies) do not use HRIS for this purpose, while $52 \%$ ( 81 companies) indicated that they do. This is a positive finding. However, as in the previous question, a large group of companies still needs to do a lot of work in this regard. Knowledge of what type of employees a company has is vital. This information should be accurate and easy to access. The performance information on HRIS will allow the company to identify its high achievers and underachievers. This will enable the company to better focus its training and development efforts and remunerate its high achievers accordingly. As in the previous question, 39 companies did not answer this question.

https://www.dcu.ie/link/cranet-international-human resource management

Table 1.54 indicates the use of HRIS for career/succession planning purposes.

The results show that $74 \%$ (110 companies) do not use HRIS for this purpose, while $25 \%$ (38 companies) indicated that they do. This is a disturbing finding. It is essential that companies do proper career/succession planning. If this planning is not done formally, the company could find itself without suitable senior managers. This will undoubtedly impact on the leadership and the company's profitability. Hence career/succession planning on HRIS will not only ensure proper planning because all the relevant information is readily available, but will also afford individual employees the opportunity to follow their own career paths. As in the previous question, 44 companies.

https://www.dcu.ie/link/cranet-international-human resource management

\section{Discussion}

Mongeli (2000) [51] illustrates that all firms in the whole world have adopted the use of e-HRM and this has drastically changed the way HR functions operate. Hendrickson (2003) [52] states that e-HRM was introduced in South Africa in the early nineties. During its inception e-HRM was supported by (HRIS) Human Resources Information System which in turn helps the HRM department to realize all its practices. Doughty (2010) [53] argues that South African intuitions managed to acquire technology the challenge exciting was how HR departments were going to effective use the e-HRM to improve their job performance and efficiency.

A survey conducted by Roffey Park institute reflects that HR functions in South Africa institutions lack foresight and credibility of the web-based technology. The survey indicates that about $75 \%$ of South African organizations needed to improve their e-HRM competencies. This is also reflected by the CRANET survey which indicates that 63\% (98 companies) do not use e-HRM for recruitment purposes. However, Erdogmus and Esen (2011) [54] reiterate that electronic recruitment has created means to attract, select and recruit new workers by the South African HR functions. E-recruitment was noted by Girard 
and Bernard (2009) [55] who concur with Erdogmus and Esen (2011) [54] that due to the use of e-HRM, there has been increased flexibility and responsiveness, enabling individuals with unique skills and talents being attracted. In addition, Johnston and Gueutal (2011) [56] establish that e-selection enabled organizations to identify suitable knowledge, skills and capabilities.

Having looked at e-recruitment it is also important to consider how South African firms handle e-performance management. Results show that 52\% (81 companies) used e-HRM for e-performance management. Shane (2009) [57] in support of these results reveals that e-HRM has an impact on organizations in providing performance appraisal. In addition, Cardy and Miller (2005) [58] state that e-HRM help South African HR practitioners to collect performance data, monitor performance and thereby measuring worker performance. There is need to reflect on the use of e-HRM on training and development. Proponents of e-HRM such as Pratheepan and Arulrajah (2012) [59] elaborate that most organizations use e-learning facilities and modules. They appraised e-training in firms as coat reduction, effective training and that it was effective for organization effectivenss. The results show that 54\% (84 companies) use of e-HRM on training and development. This was a positive finding. The results also reflect numerous benefits-for example that it allows management to gain an overall view of what skills are available in the company.

\section{Implications for the Research}

The area of Strategic Human Resources Management is young and many studies focus on the impact and the benefits. This study focuses on the adoption e-HRM, its implications and benefits also; therefore, this study aims to provide a view with a strategic character that would assist research progressing further. The special theory is the one that advocates for the strategic intent of e-HRM and studies focusing on e-HRM role in organizational transformation.

\section{Conclusions and Recommendations}

The study provides findings that e-HRM has now been fully adopted in African organisations. Many organizations rely on e-HRM for efficiency and effectiveness. In this review linking both young fields electronic-Human Resources Management and Strategic Human Resources Management has provided three contributions to literature: First, the acquiring and use of electronic-HRM is related to the strategic perspectives of HR effectiveness, the study found that there is little empirical study evidence to support that e-HRM is linked to organizational strategic outcomes. Second; review of literature fails to provide factors as keys to moderate the relationship between electronic-Human Resources Management roles and SHRM outcomes. Third, there are many Knowledge-gaps in the body of literature that needs to be strongly addressed so as to provide guidance to electronic-HRM practitioners. Future research may use opportunities to review the problems in the adoptions of e-HRM in African organizations; we be- 
lieve that this review acts as a strong foundation which motivates more research in e-HRM in an African context.

More research is needed in the same to compare the adopting levels of e-HRM in African countries; this will bring sanity in this research area. In South Africa, Nigeria and other African countries which have established e-HRM systems research is needed to explore the use of e-HRM system as a decision-making tool in most organizations.

\section{Conflicts of Interest}

The author declares no conflicts of interest.

\section{References}

[1] Ruel, H. and van der Kaap, H. (2012) E-HRM Usage and Value Creation. Does a Facilitating Context Matter? Zeitschrift für Personal Forschung, 26, 260-281. https://doi.org/10.1177/239700221202600304

[2] Nivlouei, F.B. (2014) Electronic Human Resource Management System: The Main Element in Capacitating Globalization Paradigm. International Journal of Business and Social Science, 5, 147-159.

[3] Strohmeier, S. and Kabst, R. (2014) Configurations of E-HRM-An Empirical Exploration. Employee Relations, 36, 333-353. https://doi.org/10.1108/ER-07-2013-0082

[4] Bill Gates (1999) Response to Microsoft Decision. http://www.courttv.com/archive/business/1999/1106/gates ap.html

[5] Elliot, R.H. and Tevavichulada, S. (1999) Computer Literacy and Human Resource Management: A Public/Private Sector Comparison. Public Personnel Management, 28, 259-274. https://doi.org/10.1177/009102609902800207

[6] Hooi, L.W. (2006) Implementing e-HRM: The Readiness of Small and Medium Sized Manufacturing Companies in Malaysia. Asia Pacific Business Review, 12, 465-485. https://doi.org/10.1080/13602380600570874

[7] Strohmeier, S. (2007) Research in e-HRM: Review and Implications. Human Resource Management, 17, 19-37. https://doi.org/10.1016/j.hrmr.2006.11.002

[8] Dery, K., Hall, R., Wailes, N. and Wiblen, S. (2013) Lost in Translation-An Actor-Network Approach to HRIS Implementation. Journal of Strategic Information Systems, 22, 225-237. https://doi.org/10.1016/j.jsis.2013.03.002

[9] Arvidsson, V., Holmström, J. and Lyytinen, K. (2014) Information Systems Use as Strategy Practice: A Multi-Dimensional View of Strategic Information System Implementation and Use. The Journal of Strategic Information Systems, 23, 45-61. https://doi.org/10.1016/j.jsis.2014.01.004

[10] Bondarouk, T.V., Ruel, H.J.M. and Looise, J.K. (2011) Introduction. In: Bondarouk, T., Ruel, H. and Looise, J.K., Eds., Electronic HRM in Theory and Practice, Vol. 8, Emerald Group Publishing Limited, Bingley, 11-17. https://doi.org/10.1108/S1877-6361(2011)0000008004

[11] Olivas-Luján, M.R. and Florkowski, G.W. (2009) The Diffusion of HRITs across English-Speaking Countries. In: Torres-Coronas, T. and Arias-Oliva, M., Eds., Encyclopedia of Human Resources Information Systems: Challenges in e-HRM, Information Science Reference, Hershey, 242-247.

https://doi.org/10.4018/978-1-59904-883-3.ch037 
[12] Lau, G. and Hooper, V. (2009) Adoption of E-HRM in Large New Zealand Organizations. In: Torres-Coronas, T. and Arias-Oliva, M., Eds., Encyclopedia of Human Resources Information Systems. Challenges in e-HRM, Information Science Reference, Hershey, 31-41. https://doi.org/10.4018/978-1-59904-883-3.ch006

[13] Francis, A. (2014) Steps Involved in Developing and Implementing an HRIS. http://www.upublish.info/Article/Steps-involved-in-developing-and-implementingan-HRIS/674492

[14] Burbach, R. and Royle, T. (2014) Institutional Determinants of e-HRM Diffusion Success. Employee Relations. An International Journal, 36, 354-375. https://doi.org/10.1108/ER-07-2013-0080

[15] Shanu, U. (2013) Human Resource Information Systems. http://www.slideshare.net/ujimishra1/human-resource-information-system-288397 $\underline{23}$

[16] Grant, D. and Newell, S. (2013) Realizing the Strategic Potential of e-HRM. The Journal of Strategic Information Systems, 22, 187-192. https://doi.org/10.1016/j.jsis.2013.07.001

[17] Barrett, M. and Oborn, E. (2013) Envisioning E-HRM and Strategic HR: Taking Seriously Identity, Innovative Practice, and Service. The Journal of Strategic Information Systems, 22, 252-256. https://doi.org/10.1016/j.jsis.2013.07.002

[18] Khera, S.N. and Gulati, K. (2021) Human Resource Information System and Its Impact on Human Resource Planning: A Perceptual Analysis of Information Technology Companies. IOSR Journal of Business and Management (IOSRJBM), 3, 6-13. https://doi.org/10.9790/487X-0360613

[19] Ghazala, I. and Habib, J. (2012) Human Resource Strategies. Journal of Business and Management, 3, 6-13.

[20] Tripathi, K.P. (2011) A Study of Information Systems in Human Resource Management (HRM). International Journal of Computer Applications, 22, 9-13.

https://doi.org/10.5120/2606-3635

[21] Chiemeke, C. (2011) Human Resource Information Systems: An Integrated Research Agenda. Advanced Series in Management, Volume 8, Emerald Group Publishing Limited, Bingley, 21-39.

https://doi.org/10.1108/S1877-6361(2011)0000008006

[22] Gupta, A. and Saxen, S. (2011) Employees' Satisfaction towards E-HRM in Service Organizations. Gurukul Business Review, 7, 41-52.

[23] Krishna, C.Y.S. and Bhaskar, S.V. (2011) Assessment of Support and Benefits of HRIS in Medium-Scale Textile Industries. International Journal of Research in Economics and Social Sciences, 1, 48-57.

[24] Olivas-Lujan, M.R., Ramire, Z.J. and Zapata-Cantu, L. (2007) E-HRM in Mexico: Adapting Innovations for Global Competitiveness. International Journal of Manpower, 28, 418-434. https://doi.org/10.1108/01437720710778402

[25] Strohmeier, S. and Kabst, R. (2009) Organizational Adoption of e-HRM in Europe: An Empirical Explanation of Major Adoption Factors. Journal of Managerial Psychology, 24, 482. https://doi.org/10.1108/02683940910974099

[26] Bell, B.S., Lee, S.-W. and Yeung, S.K. (2006) The Impact of E-HR on Professional Competence in HRM: Implications for the Development of HR Professionals. $\mathrm{Hu}$ man Resource Management, 45, 295-308. https://doi.org/10.1002/hrm.20113

[27] Parry, E. and Tyson, S. (2011) Desired Goals and Actual Outcomes of e-HRM. Human Resource Management Journal, 21, 335-354.

https://doi.org/10.1111/j.1748-8583.2010.00149.x 
[28] Strohmeier, S. (2009) Concepts of e-HRM Consequences: A Categorizations, Review and Suggestion. The International Journal of Human Resource Management, 20, 528-543. https://doi.org/10.1080/09585190802707292

[29] Ruta, C.D. (2009) HR Portal Alignment for the Creation and Development of Intellectual Capital. The International Journal of Human Resource Management, 20, 562-577. https://doi.org/10.1080/09585190802707318

[30] Marler, J.H. and Fisher, S.L. (2013) An Evidence-Based Review of e-HRM and SHRM. Human Resource Management Review, 23, 18-36. https://doi.org/10.1016/j.hrmr.2012.06.002

[31] Barney, J.B. (1991) Firm Resources and Sustained Competitive Advantage. Journal of Management Studies, 17, 99-120. https://doi.org/10.1177/014920639101700108

[32] Lengnick-Hall, C.A. and Lengnick-Hall, M.L. (2009) HR, ERP, and Competitive Advantage. Human Resource Management, 45, 179-194. https://doi.org/10.1002/hrm.20103

[33] Ruël, H.J.M. and Bondarouk, T. (2009) Electronic Human Resource Management: Challenges in the Digital Era. The International Journal of Human Resource Management, 20, 505-551. https://doi.org/10.1080/09585190802707235

[34] Kaur, P. (2013) E-HRM: A Boon or Bane? ANVESHANAM a National Journal of Management, 1, 35-36.

[35] Lawrence, P.R. and Lorsch, J.W. (1967) Differentiation and Integration in Complex Organizations. Administrative Science Quarterly, 12, 1-47.

https://doi.org/10.2307/2391211

[36] Wright, P.M. and Dyer, L. (2000) People in the E-Business: New Challenges, New Solutions. CAHRS Working Paper 00-11, Cornell, Ithaca.

[37] Lengnick-Hall, M.L. and Moritz, S. (2003) The Impact of e-HR on the Human Resource Management Function. Journal of Labor Research, 24, 365-379.

https://doi.org/10.1007/s12122-003-1001-6

[38] Kulkarni, S. (2012) E-HRM Implementation. http://sachidanandkulkarni.blogspot.com/2012/04/e-hrm-implementation.html

[39] Kariznoee, A., Afshani, M. and Moghadam, M.R.H. (2012) The Examine of Effect of e-HRM on Employee's Job Performance. Advanced Research in Economic and Management Sciences (AREMS), 6, 275-282.

[40] Lepak, D.P. and Snell, S.A. (1998) Virtual HR: Strategic Human Resource Management in the 21st Century. Human Resource Management Review, 8, 215-234. https://doi.org/10.1016/S1053-4822(98)90003-1

[41] Dhamija, P. (2012) E-Recruitment: A Roadmap towards E-Human Resource Management. Journal of Arts, Science and Commerce, 3.

[42] Tong, D.Y.K. (2009) A Study of e-Recruitment Technology Adoption in Malaysia. Industrial Management and Data Systems, 109, 281-300. https://doi.org/10.1108/02635570910930145

[43] Bell, J. (2007) E-Learning: Your Flexible Development Friend. Development and Learning in Organizations, 21, 7-9. https://doi.org/10.1108/14777280710828558

[44] Kaplan-Leiserson, E. (2002) E-Learning Glossary. http://www.learningcircuits.org/glossary.html

[45] Sambrook, S. (2003) E-Learning in Small Organizations. Education + Training, 45, 506-516. https://doi.org/10.1108/00400910310508892

[46] Comacchio, A. and Scapolan, A. (2004) The Adoption Process of Corporate e-Learning 
in Italy. Education+ Training, 46, 315-325.

https://doi.org/10.1108/00400910410555222

[47] Manjunath, V.S. and Rajesh, C.N. (2012) Competency Based Compensation System-As a Strategic Human Resource Technique. International Journal of Manpower, 38, 780-810.

[48] Dulebohn, J.H. and Marler, J.H. (2005) E-Compensation: The Potential to Transform Practice? In: Gueutal, H.G. and Stone, D.L., Eds., The Brave New World of e-HR: Human Resources Management in the Digital Age, John Wiley and Sons, Inc., San Francisco, 166-189.

[49] Snell, S.A., Shadur, M.A. and Wright, P.M. (2000) Human Resources Strategy: The Era of Our Ways. CAHRS Working Paper Series. Paper 95.

[50] Bondarouk, T. (2009) Handbook of Research on e-Transformation and Human Resources 65 Management Technologies: Organizational Outcomes and Challenges. Information Science Reference, Hershey.

https://doi.org/10.4018/978-1-60566-304-3

[51] Mongelli, F.P. (2000) Benefits and Costs of Participating in EMU: An Extension. Rivista di Politica Economica, 2.

[52] Hendrikson, A. (2003) Human Resource Information Systems: Backbone Technology of Contemporary Human Resources. Journal of Labour Research, 24, 382-387. https://doi.org/10.1007/s12122-003-1002-5

[53] Doughty, M. (2010) The Role of e-HR and Organisation Effectiveness. Workplace Performance Technologies Ltd. http://www.workinfo.com/free/downloads/301.htm

[54] Erdoğmuş, İ. and Çalışkan, M. (2011) Online Group Buying: What Is There for the Consumers? Procedia Social and Behavioral Sciences, 24, 308-316.

https://doi.org/10.1016/j.sbspro.2011.09.138

[55] Girard, A. and Bernard, F. (2009) E-Recruitment: New Practices, New Issues: An Exploratory Study. In: Human Resource Information Systems, INSTICC Press, Montpellier, 39-48.

[56] Johnson, R.D. and Gueutal, H.G. (2011) Transforming HR through Technology: The Use of e-HR and Human Resource Information System in Organizations. SHRM Effective Practices Guidelines Series.

[57] Shane, L. (2009) Development and Validation of a Measure That Examines Attitudes towards e-HRM Practices. Thesis, University of South Africa, Pretoria.

[58] Cardy, R.L. and Miller, J.S. (2005) E-HR and Performance Management: A Consideration of Positive Potential and the Dark Side. In: Greutal and Stone, Eds., The Brave New World of e-HR, Jossey-Bass, San Francisco, 138-165.

[59] Pratheepan, S. and Arulrajah, A. (2012) Application of Electronic Human Resource Management (e-HRM) Practices and Its Effectiveness in Selected Private Banks in Sri Lanka. University of Colombo, Colombo. 